\title{
MULHER E DIREITOS HUMANOS: POR QUE PRECISAMOS TRATAR DESTE TEMA?
}

\section{WOMEN AND HUMAN RIGHTS: WHY DO WE NEED TO DEAL WITH THIS ISSUE?}

\author{
André R.C. Fontes* \\ Reis Friede ${ }^{* \star}$
}

Resumo: O presente artigo foi organizado a partir do discurso dos autores, na abertura do evento Mulher, Poder e Democracia, realizado em 2018, no Centro Cultural Justiça Federal. O texto faz uma breve apresentação dos direitos humanos e segue argumentando acerca da necessidade de se debater tais direitos, em face de problemas ainda hoje enfrentados pelas mulheres na luta contra o assedio sexual e contra o que foi recentemente conceituado como feminicídio, que significa a perseguição e morte intencional de pessoas do sexo feminino. Discute, ainda, a necessidade de políticas públicas de efetivação dos direitos da mulher, o que está em perfeita sintonia com o Objetivo 5, ODS 5, da Agenda 2030 para o Desenvolvimento Sustentável da Organização das Nações Unidas, ONU.

Palavras-chave: Agenda 2030. Desenvolvimento sustentável. Igualdade de poder entre homens e mulheres.

Abstract: This paper was organized from the speech of the authors, in the opening of the event Women, Power and Democracy, held in 2018, in the Cultural Center of Federal Justice. The text makes a brief presentation of human rights and argue about the need to discuss such rights, considering the problems still faced by women, in the fight against sexual harassment and against what has been recently conceptualized as femicide, it means the persecution and intentional death of female people. It also discusses the need for public policies to effect women's rights, which is in perfect alignment with Objective 5, ODS 5, of 2030 Agenda for the Sustainable Development of the United Nations, UN.

\footnotetext{
* Doutor em Direito Civil pela Universidade do Estado do Rio de Janeiro - UERJ (2005), Doutor em Filosofia pela Universidade Federal do Rio de Janeiro - UFRJ (2007), Doutor em Ciências em História das Ciências, das Técnicas e Epistemologia pela Universidade Federal do Rio de Janeiro - UFRJ (2007), Doutor em Ciências Ambientais e Florestais pela Universidade Federal Rural do Rio de Janeiro - UFRRJ (2015), Mestre em Direito Civil pela Universidade do Estado do Rio de Janeiro UERJ (2002) e Mestre em Direito Constitucional pela Universidade Federal Fluminense - UFF (2013). Professor Adjunto da Universidade Federal do Estado do Rio de Janeiro - UNI-RIO. Professor no Programa de Pós-Graduação em Direito da Universidade Federal do Estado do Rio de Janeiro UNIRIO. Desembargador do Tribunal Regional Federal da $2^{\mathrm{a}}$ Região (Rio de Janeiro e Espírito Santo).

${ }^{* *}$ Desembargador Federal, Diretor do Centro Cultural da Justiça Federal (CCJF), Mestre e Doutor em Direito. Professor e Pesquisador do Programa de Mestrado em Desenvolvimento Local do Centro Universitário Augusto Motta (UNISUAM), no Rio de Janeiro. Site: https://reisfriede.wordpress.com/. Email: reisfriede@hotmail.com
} 
Keywords: 2030 Agenda. Sustainable Development. Equality of power between men and women. 


\section{INTRODUÇÃO}

Em março de 2018, o Centro Cultural Justiça Federal realizou durante uma semana o evento Mulher, Poder e Democracia, com a finalidade de discutir o Objetivo 5, da Agenda 2030 para o Desenvolvimento Sustentável da ONU, cujo Objetivo 5 versa sobre o "empoderamento das mulheres". Várias mesas-redondas foram organizadas no decorrer da semana, mas a primeira Mesa, em que os autores foram debatedores, discutiu exatamente a temática intitulada Mulher e Direitos Humanos.

Outras mesas-redondas abordaram aspectos diversos, como assédio, política, empoderamento, trabalho, saúde, educação, cultura e também do papel da mulher, do feminino, na construção de um planeta mais sustentável, pois, como diria o Papa Francisco, a Terra é a nossa casa comum.

Os debates do evento mostraram conquistas importantes das mulheres, principalmente no âmbito da magistratura, mas também evidenciou desafios pela frente, mas todos amparados nas perspectivas do objetivo 5 da Agenda 2030 do Desenvolvimento Sustentável da ONU, que trata da igualdade de gênero e do empoderamento de mulheres e meninas.

Tal objetivo visa intensificar especialmente o combate às discriminações e violências baseadas no gênero e eliminar todas as práticas nocivas, como os casamentos forçados e prematuros de crianças e mutilações genitais femininas.

Visa também reconhecer e valorizar o trabalho doméstico não remunerado, por meio da disponibilização de serviços públicos, infraestrutura e políticas de proteção social, bem como a promoção da responsabilidade compartilhada dentro do lar e da família. E, ainda, garantir a participação plena e efetiva das mulheres e a igualdade de oportunidades para a liderança em todos os níveis de tomada de decisão na vida política, econômica e pública etc. Todas essas importantes questões inscritas no Objetivo 5 da ONU estão no escopo dos Direitos Humanos, daí a importância em debatê-los e defendê-los amplamente. 


\section{DIREITOS HUMANOS}

Os direitos humanos podem ser entendidos como aqueles que possibilitam ao cidadão viver com dignidade. Envolvem direitos civis, políticos, sociais, individuais ou coletivos. Conforme pontuado pelas Nações Unidas, algumas das características mais importantes dos direitos humanos são:

- Os direitos humanos são fundados sobre o respeito pela dignidade e o valor de cada pessoa;

- Os direitos humanos são universais, o que quer dizer que são aplicados de forma igual e sem discriminação a todas as pessoas;

- Os direitos humanos são inalienáveis, e ninguém pode ser privado de seus direitos humanos; eles podem ser limitados em situações específicas. Por exemplo, o direito à liberdade pode ser restringido se uma pessoa é considerada culpada de um crime diante de um tribunal e com o devido processo legal;

- Os direitos humanos são indivisíveis, inter-relacionados e interdependentes, já que é insuficiente respeitar alguns direitos humanos e outros não. Na prática, a violação de um direito vai afetar o respeito por muitos outros;

- Todos os direitos humanos devem, portanto, ser vistos como de igual importância, sendo igualmente essencial respeitar a dignidade e o valor de cada pessoa. (ORGANIZAÇÃO DAS NAÇÕES UNIDAS, 2018).

Os direitos humanos podem ser restringidos quando em conflito com outros direitos também considerados fundamentais. Nos casos de aplicação de pena privativa de liberdade, o direito à liberdade de um cidadão é limitado, pois conflitou com o direito à vida, integridade física, segurança, etc., dos demais cidadãos.

A Declaração Universal dos Direitos Humanos (DUDH) (ORGANIZAÇÃO DAS NAÇÕES UNIDAS, [1948]), que este ano completará 70 anos, é um documento marco na história dos direitos humanos. Elaborada por representantes de diferentes origens jurídicas e culturais de todas as regiões do mundo, a Declaração foi proclamada pela Assembleia Geral das Nações Unidas em Paris, em 10 de dezembro de 1948, por meio da Resolução 217 A (III) da Assembleia Geral como uma norma comum a ser alcançada por todos os povos e nações. Ela estabeleceu, pela primeira vez, a proteção universal dos direitos humanos. 
Sendo assim, desde o pós-guerra, passou-se a compreender a dignidade humana como principal objetivo dos estados democráticos. Vale ressaltar a lição de Osvaldo Canela Junior no sentido de que os direitos individuais do cidadão constituem o maior compromisso e, inclusive, a razão de ser do Estado Democrático de Direito. Especificamente no caso do Brasil, esta condição pode ser vista de forma objetiva quando analisamos os tratados internacionais firmados pelo país, nos quais é patente o compromisso com o respeito e a promoção da dignidade da pessoa humana como fundamento do próprio Estado. Nas palavras do autor:

\begin{abstract}
A institucionalização dos direitos humanos é o consectário lógicojurídico da Declaração Universal dos Direitos Humanos e permite agregar aos valores éticos a força normativa da Constituição. Representa a implementação formal, pelos Estados, do novel sistema ético de referência, mediante a adequação de suas normas constitucionais internas ao novo modelo. (...) O que se altera no panorama jurídico interno dos Estados é o novo referencial ético, consubstanciado no consenso das diversas nações. Os direitos humanos, portanto, passam a ter uma nova compreensão, lastreada no compromisso ético de progressiva e absoluta proteção em nível mundial. (CANELA JUNIOR, 2011. p. 36-37).
\end{abstract}

Considerando os direitos humanos, portanto, como objetivo central dos Estados, a sua promoção deve ser buscada de forma mais ampla possível, através de políticas públicas que proporcionem dignidade e bem estar aos cidadãos.

\title{
3 E POR QUE PRECISAMOS FALAR DE DIREITOS HUMANOS ESPECIFICAMENTE PARA MULHERES?
}

Essa pergunta possui muitas respostas. A primeira é que os direitos políticos das mulheres não são plenamente exercidos; a segunda é porque o direito de ir e de vir é restringido em razão do assédio sexual nas ruas e locais de trabalho. A terceira é porque o direito à vida da mulher ainda é ameaçado, pois elas ainda sofrem com violência de gênero; a quarta é porque as mulheres, principalmente as pobres, sofrem com questões relacionadas ao aborto, que no Brasil é uma questão de saúde pública. A quinta é porque muitas mulheres ainda realizam casamentos forçados e a sexta, entre tantas outras, é porque as mulheres precisam atingir patamares de desenvolvimento econômico, que ainda hoje não possuem (ZAPATER, 2015). 
Segundo a diretora-executiva da ONU Mulheres, Phumzile Mlambo-Ngcuka, "a violência contra a mulher é a violação de direitos humanos mais tolerada no mundo". Talvez porque praticada dentro dos próprios lares, por chamados "homens de bem", pessoas sem ficha criminal, com trabalho e boa convivência social. Talvez por acontecer em todas as nações, todas as raças, classes sociais, religiões etc.

Por sua vez, a administradora do Programa das Nações Unidas para o Desenvolvimento (PNUD), Helen Clark, destaca que:

a violência contra as mulheres ocorre em todos os continentes e em todos os países, fazendo desta uma das mais disseminadas violações dos direitos humanos por todo o mundo. As estatísticas são desanimadoras: uma em cada três mulheres em todo o mundo sofreu violência física ou sexual, na grande maioria, vítimas do próprio parceiro. (ORGANIZAÇÃO DAS NAÇÕES UNIDAS, 2018)

A violência contra as mulheres, designada violência de gênero, é considerada um problema de saúde pública pela Organização Mundial da Saúde desde 1990. No Brasil, esse é um problema muito sério que precisa ser debatido. A maioria dos atos violentos ocorre no ambiente doméstico e a vítima geralmente conhece o agressor. Violências baseadas em gênero compreendem agressões de caráter físico, psicológico, sexual e patrimonial e podem culminar na morte da mulher por suicídio ou por homicídio.

Os homicídios decorrentes de conflitos de gênero têm sido denominados feminicídios, termo de cunho político e legal para se referir a esse tipo de morte. $O$ termo feminicídio, como "o assassinato de mulheres por serem-no" é uma das mais sangrentas e visíveis formas de violência. Normalmente é precedido por violência sexual e outros atos que ameaçam a dignidade das mulheres, tanto por agressores conhecidos como desconhecidos (RODRÍGUEZ, 2013). O termo foi usado pela primeira vez em 1976, em um tribunal de direitos humanos e corresponde a qualquer manifestação ou exercício de relações desiguais de poder entre homens e mulheres que culmina com a morte de uma ou várias mulheres pela própria condição de ser mulher.

Sousa (2016) reflete sobre a necessidade de explicar o feminicidio, seus contornos, enquanto forma específica de violência contra as mulheres e de 
encontrar as motivações que transformam um episódio extremo de conflito doméstico num fenômeno que se assemelha a outros processos de exterminação seletiva de seres humanos como o genocídio.

Conforme o Anuário Brasileiro de Segurança Pública (2017), o Brasil teve mais de 600 casos de violência doméstica por dia em 2017. Foram 221.238 registros e o número de mulheres assassinadas aumentou $6,1 \%$ em relação a 2016 (ACAYABA; PAULO, 2018). Desse total, 1.133 foram vítimas de feminicídio.

Em 2015, a Faculdade Latino-Americana de Ciências Sociais (Flacso), com o apoio do escritório no Brasil da ONU Mulheres, da Organização Pan-Americana da Saúde/Organização Mundial da Saúde (OPAS/OMS) e da Secretaria Especial de Políticas para as Mulheres (SPM) do Ministério das Mulheres, da Igualdade Racial e dos Direitos Humanos, elaborou o Mapa da Violência 2015: Homicídio de Mulheres no Brasil, o qual informa o seguinte:

- Dos 4.762 assassinatos de mulheres registrados em 2013 no Brasil, $50,3 \%$ foram cometidos por familiares, sendo que em $33,2 \%$ destes casos o crime foi praticado pelo parceiro ou ex. Essas quase 5 mil mortes representam 13 homicídios femininos diários em 2013.

- Entre 1980 e 2013, 106.093 brasileiras foram vítimas de assassinato; e, de 2003 a 2013, o número de vítimas do sexo feminino cresceu de 3.937 para 4.762 , ou seja, mais de $21 \%$ nessa década.

- Enquanto quase a metade dos homicídios masculinos acontece na rua e o domicílio aparece pouco como local do crime, nos homicídios femininos, mesmo considerando que $31,2 \%$ dos crimes acontecem na rua, a residência da vítima como local do assassinato aparece em $27,1 \%$ dos casos, o que indica que a casa é um local de alto risco para as mulheres.

- Tanto para homens como para mulheres, armas de fogo e objetos cortantes e contundentes são os meio mais usados nos homicídios. Mas enquanto para os homens as mortes são majoritariamente provocadas por tiros $(73,2 \%$ dos casos), no caso das mulheres essa incidência é menor, de $48,8 \%$. Já o uso de objetos como facas e paus são mais frequentes nos homicídios femininos, o que, segundo especialistas, pode indicar crimes de ódio ou por motivos fúteis.

- Diversos estados brasileiros apresentaram forte aumento no número de assassinatos de mulheres na década, como Roraima, onde as taxas mais que quadruplicaram $(343,9 \%)$, ou Paraíba, onde mais que triplicaram $(229,2 \%)$. Entre 2006 , ano da entrada em vigor da Lei Maria da Penha, e 2013, cinco estados haviam registrado quedas nas taxas: Rondônia, Espírito Santo, Pernambuco, São Paulo 
e Rio de Janeiro. (FACULDADE LATINO-AMERICANA DE CIÊNCIAS SOCIAIS, 2015, grifo nosso).

Diante desses dados, observa-se que o feminicídio possui características próprias, não se confundindo com o homicídio de forma geral. Trata-se de crimes cometidos em razão da condição de mulher da vítima e, geralmente, pelos próprios parceiros ou outros membros da família, pessoas sem antecedentes criminais e não envolvidas em organizações criminosas.

\section{O OBJETIVO 5 DA AGENDA 2030 PARA O DESENVOLVIMENTO SUSTENTÁVEL DA ORGANIZAÇÃO DAS NAÇÕES UNIDAS}

A Agenda 2030 da ONU foi firmada na sede das Nações Unidas em Nova York de 25 a 27 de setembro de 2015, por chefes de Estado e de Governo e altos representantes, tendo por objetivo traçar os novos Objetivos Globais de Desenvolvimento Sustentável.

O Objetivo 5 da Agenda 2030 para o Desenvolvimento Sustentável traça metas para alcançar a igualdade de gênero e empoderar todas as mulheres e meninas. Abaixo segue o conteúdo do objetivo 5 , apresentado em itens que abrangem diversos aspectos da promoção da dignidade da mulher:

\section{Objetivo 5. Alcançar a igualdade de gênero e empoderar todas as mulheres e meninas}

5.1 Acabar com todas as formas de discriminação contra todas as mulheres e meninas em toda parte

5.2 Eliminar todas as formas de violência contra todas as mulheres e meninas nas esferas públicas e privadas, incluindo o tráfico e exploração sexual e de outros tipos

5.3 Eliminar todas as práticas nocivas, como os casamentos prematuros, forçados e de crianças e mutilações genitais femininas

5.4 Reconhecer e valorizar o trabalho de assistência e doméstico não remunerado, por meio da disponibilização de serviços públicos, infraestrutura e políticas de proteção social, bem como a promoção da responsabilidade compartilhada dentro do lar e da família, conforme os contextos nacionais

5.5 Garantir a participação plena e efetiva das mulheres e a igualdade de oportunidades para a liderança em todos os níveis de tomada de decisão na vida política, econômica e pública

5.6 Assegurar o acesso universal à saúde sexual e reprodutiva e os direitos reprodutivos, como acordado em conformidade com 0 
Programa de Ação da Conferência Internacional sobre População e Desenvolvimento e com a Plataforma de Ação de Pequim e os documentos resultantes de suas conferências de revisão

5.a Realizar reformas para dar às mulheres direitos iguais aos recursos econômicos, bem como o acesso a propriedade e controle sobre a terra e outras formas de propriedade, serviços financeiros, herança e os recursos naturais, de acordo com as leis nacionais

5.b Aumentar o uso de tecnologias de base, em particular as tecnologias de informação e comunicação, para promover o empoderamento das mulheres

5.c Adotar e fortalecer políticas sólidas e legislação aplicável para a promoção da igualdade de gênero e o empoderamento de todas as mulheres e meninas em todos os níveis. (ORGANIZAÇÃO DAS NAÇÕES UNIDAS, 2015)

Nota-se, portanto, a amplitude dos desafios da comunidade internacional para efetivar os direitos humanos da mulher. Não basta apenas punir agressores, em uma ação repressora do Estado. É necessária uma mudança de mentalidade, cultural, mediante ações afirmativas capazes de levar o gênero feminino a outro patamar. Toda a sociedade deve ser levada a pensar a questão e para isso são necessárias políticas públicas.

Nancy Fraser (2006) ensina que há políticas públicas de redistribuição, que objetivam redistribuir os recursos existentes na sociedade, e as de reconhecimento, cuja finalidade é reconhecer grupos sociais vulneráveis como partícipes da arena social, sem que lhes sejam destinados recursos financeiros ou serviços sociais como saúde, educação, moradia etc. Deste modo, não apenas os direitos fundamentais ditos sociais exigiriam a atuação positiva do Estado, mas também os direitos individuais de liberdade e igualdade.

No âmbito da redistribuição, busca-se maior distribuição de renda; no do reconhecimento, busca-se ser aceito e tratado com dignidade, apesar de possuir características diferentes. Enquanto as políticas sociais objetivam igualar as pessoas, as culturais buscam diferenciá-las. (FRASER, 2007).

Nas palavras da autora:

A "luta por reconhecimento" está rapidamente se tornando a forma paradigmática de conflito no final do século XX. Demandas por "reconhecimento da diferença" dão combustível às lutas de grupos mobilizados sob as bandeiras da nacionalidade, etnicidade, "raça", gênero e sexualidade. Nestes conflitos "pós-socialistas", a identidade 
de grupo suplanta o interesse de classe como o meio principal da mobilização política. A dominação cultural suplanta a exploração como a injustiça fundamental. $\mathrm{E}$ o reconhecimento cultural toma o lugar da redistribuição socioeconômica como remédio para a injustiça e objetivo da luta política. (FRASER, 2006, p. 231-239).

No caso da mulher, a fim de atender aos objetivos da ONU, são necessárias políticas públicas de ambos os tipos, de redistribuição e de reconhecimento, ou seja, voltadas para o empoderamento econômico da mulher e melhoria das condições de vida da mulher de baixa renda, como saúde, educação, saneamento básico, moradia etc., bem como políticas voltadas para o reconhecimento e valorização da mulher, como cotas em cargos decisórios, educativas contra a violência, enfim, de conscientização geral.

\section{CONCLUSÃO}

O presente trabalho pretendeu mostrar de forma geral a grande necessidade de se discutir os direitos humanos especificamente para as mulheres, apontando diversos desafios no que toca ao reconhecimento da mulher e o seu empoderamento.

De fato, são inúmeros os aspectos a serem corrigidos na sociedade, global e especificamente na brasileira, que possui números assustadores de violência contra a mulher e uma legislação arcaica no tocante ao aborto e à adoção.

Conforme a Agenda 2030 da ONU previu em seu Objetivo 5, não se trata apenas da criminalização do feminicídio, mas também da mudança de paradigmas econômicos, profissionais, culturais, permitindo à mulher viver com dignidade, fazer as suas escolhas de forma independente e ser protegida pelo Estado.

Diante do exposto, o Brasil, como verdadeiro aspirante a Estado Democrático de Direito, à luz dos princípios emanados da Carta Magna, e que tem nesta, a defesa dos direitos humanos, sexuais e reprodutivos das mulheres, princípios estes consubstanciados por importantes tratados internacionais de direitos humanos adotados por nosso país tem a obrigação jurídica e ética de implementar políticas públicas em favor das mulheres, tornando-se verdadeiramente uma 
democracia em sua plenitude material e efetiva e deixando de ser apenas uma democracia formal.

\section{REFERÊNCIAS}

ACAYABA, Cíntia; PAULO, Paula Paiva. Brasil tem mais de 600 casos de violência doméstica por dia em 2017. Globo.com., São Paulo, 9 jun. 2018. Disponível em: <https://g1.globo.com/sp/sao-paulo/noticia/2018/08/09/brasil-tem-mais-de-600-casosde-violencia-domestica-por-dia-em-2017.ghtml>. Acesso em: 10 ago. 2018.

CANELA JUNIOR, Osvaldo. Controle judicial de políticas públicas. São Paulo: Saraiva, 2011.

FACULDADE LATINO-AMERICANA DE CIÊNCIAS SOCIAIS. Mapa da violência 2015: homicídio de mulheres no Brasil. Brasília, DF, 9 nov. 2015. Notícia. Disponível em: <http://dossies.agenciapatriciagalvao.org.br/violencia/pesquisa/mapa-daviolencia-2015-homicidio-de-mulheres-no-brasil-flacsoopas-omsonu-mulheresspm2015/>. Acesso em: 10 ago. 2018.

FRASER, Nancy. Da redistribuição ao reconhecimento? Dilemas da justiça numa era "pós-socialista". Tradução:Julio Assis Simões. Cadernos de campo, São Paulo, n. 14-15, p. 231-239, 2006.

. Reconhecimento sem ética? Tradução: Ana Carolina Freitas Lima Ogando; Maria Prandini Fraga Assis. Lua nova, São Paulo, n. 70, p. 101-138, 2007.

ORGANIZAÇÃO DAS NAÇÕES UNIDAS. O que são os direitos humanos? 2018. Disponível em: https://nacoesunidas.org/direitoshumanos/. Acesso em: 10 ago. 2018.

. 'Violência contra a mulher é a violação de direitos humanos mais tolerada no mundo', afirma ONU. 25 nov. 2015. Disponível em: $<$ https://nacoesunidas.org/violencia-contra-a-mulher-e-a-violacao-de-direitoshumanos-mais-tolerada-no-mundo-afirma-onu/>. Acesso em: 10 ago. 2018.

Declaração Universal dos Direitos Humanos. [1948]. Disponível em: $\overline{<h t t p s: / / n a c o e s u n i d a s . o r g / d i r e i t o s h u m a n o s / d e c l a r a c a o />. ~ A c e s s o ~ e m: ~} 10$ ago. 2018.

RODRÍGUEZ, Marta. Isabel Agatón: el feminicidio se puede prevenir y se debe evitar. Mujeres en Red: el periódico feminista, fev. 2013. Disponível em <http://www.mujeresenred.net/spip.php?article2097>. Acesso em: 17 jul. 2016. 
SOUSA, Tania Teixeira Laky de. Feminicídio: uma leitura a partir da perspectiva feminista. ex æquo, Lisboa, n. 34, p. 13-29, 2016. Disponível em:

<http://www.scielo.mec.pt/pdf/aeq/n34/n34a03.pdf>. Acesso em: 20 jul. 2018.

ZAPATER, Maíra. Porque (ainda) falar em direitos humanos das mulheres. Carta Capital, 6 mar. 2015. Disponível em:

<http://justificando.cartacapital.com.br/2015/03/06/porque-ainda-falar-em-direitoshumanos-das-mulheres/>. Acesso em: 10 ago. 2018. 